\title{
Effects of Climate Change on the Seasonality of Weather for Tourism in Alaska
}

\author{
GONGMEI YU, ${ }^{1,2}$ ZVI SCHWARTZ1 and JOHN E. WALSH ${ }^{3}$
}

(Received 9 May 2008; accepted in revised form 11 March 2009)

\begin{abstract}
This study presents a method to identify and categorize seasonal patterns of weather conducive to specific tourism activities, using a tourism climate index based on hourly weather data. We examined changes in seasonal weather patterns in recent decades (1942-2005) at two Alaska destinations, King Salmon and Anchorage. The results indicate that climate warming has had both positive and negative effects on opportunities for tourism. The overall weather conditions for sightseeing in King Salmon have improved significantly with a lengthening of the season, which now starts 10 days earlier than in the 1940s. Conversely, weather conditions for skiing in Anchorage have deteriorated, primarily because weather suitable for skiing now ends about nine days earlier than in the 1940s. Future climate change (i.e., continued warming) is very likely to extend the sightseeing season at King Salmon, but is less likely to improve the quality of the peak season. At the same time, though warming is likely to shorten the total time for skiing each year at Anchorage, it is also likely to improve the quality of the winter season and increase the frequency of years when skiing quality peaks in mid-winter. For both activities, changes of spring temperature will have the greatest impact on tourism weather. Tourism indices such as the one presented here can be tailored to the requirements of specific tourist activities, providing an opportunity for improved tourism planning and decision making.
\end{abstract}

Key words: climate change, tourism, climate impacts, seasonality, climate index

RÉSUMÉ. Cette étude présente une méthode d'identification et de catégorisation des variations météorologiques saisonnières propices à des activités touristiques particulières et ce, à l'aide d'un indice climatique touristique reposant sur des données météorologiques horaires. Nous avons examiné les changements ayant caractérisé les variations météorologiques saisonnières de décennies récentes (1942-2005) à deux destinations de l'Alaska, soit King Salmon et Anchorage. Les résultats indiquent que le réchauffement climatique a eu des incidences à la fois positives et négatives sur les débouchés touristiques. Dans l'ensemble, les conditions météorologiques propices aux visites touristiques à King Salmon se sont améliorées considérablement en ce sens que la saison est maintenant plus longue, celle-ci commençant dix jours plus tôt que dans les années 1940. Par contre, les conditions météorologiques pour le ski se sont détériorées à Anchorage, principalement parce que le temps se prêtant au ski se termine maintenant environ neuf jours plus tôt que dans les années 1940. Les changements climatiques à venir (c'est-à-dire le réchauffement climatique continu) auront vraisemblablement pour effet de prolonger la saison des visites touristiques à King Salmon, sans que cela n'améliore pour autant la qualité de la haute saison. Par la même occasion, bien que le réchauffement aura probablement pour effet de raccourcir le nombre total de jours de ski à Anchorage chaque année, il aura vraisemblablement pour effet d'améliorer la qualité de la saison hivernale et d'augmenter la fréquence des années où la qualité du ski sera à son meilleur au milieu de l'hiver. Dans les deux cas, les changements caractérisant les températures enregistrées au printemps auront les plus grandes incidences sur les conditions météorologiques pour le tourisme. Les indices du tourisme, tel que celui présenté ici, peuvent être adaptés aux exigences d'activités touristiques spécifiques, ce qui donne la possibilité de mieux planifier les activités touristiques et de prendre des décisions à meilleur escient.

Mots clés : changement climatique, tourisme, incidences climatiques, saisonnalité, indice climatique

Traduit pour la revue Arctic par Nicole Giguère.

\section{INTRODUCTION}

Tourism, which brings more than 1.5 million visitors who spend about \$1.6 billion annually, is one of the largest industries in Alaska's economy (Alaska Travel Industry
Association, 2006). Tourism is also one of Alaska's largest generators of employment. Nature-based tourism is an important component of the tourism industry in North America (Scott et al., 2007), and Alaska is no exception. Summer tourism activities include sightseeing, wildlife

\footnotetext{
${ }^{1}$ Department of Recreation, Sport and Tourism, 1206 South Fourth Street, University of Illinois at Urbana-Champaign, Champaign, Illinois 61820, USA

${ }^{2}$ Present address: IMPAQ International, LLC, 10420 Little Patuxent Parkway, Suite 300, Columbia, Maryland 21044, USA; gyu@impaqint.com

${ }^{3}$ International Arctic Research Center, University of Alaska Fairbanks, PO Box 757340, Fairbanks, Alaska 99775-7340, USA

(C) The Arctic Institute of North America
} 
watching, hiking, boating, and fishing, while winter activities include snowboarding, downhill skiing, cross-country skiing, and Northern Lights viewing. These outdoor tourism activities depend on the state's scenic beauty, glaciers, wilderness setting, wildlife, and other natural attributes. Visitor surveys indicate that more than $80 \%$ of Alaska's visitors travel for vacation and pleasure (Alaska Office of Tourism Development, 2006). Outdoor activities such as wildlife viewing and sightseeing are considerably more popular (56\% and $44 \%$ of visitors, respectively) than indoor activities such as cultural attractions (18\%).

Climate plays a significant role in nature-based tourism, affecting it both indirectly and directly. Indirect impacts include changes in ecosystems and geography on which tourism depends. For example, studies by Slayback et al. (2003), Hawkins and Porter (2003), and Bartlein et al. (1997) indicate that climate warming has significant ecosystem impacts such as the northward shift of the grassland eco-zone, diversity and abundance of species, and the redistribution of flora and fauna. The threatened status of polar bears, for example, has implications for ecotourism in northern Canada. Lemelin and Smale (2006) show that the key factor in the satisfaction of wildlife viewers at Churchill, Manitoba, is the number of polar bears seen. In other areas, such as Mt. McKinley National Park and Katmai National Park in Alaska, wildlife viewing is a major activity that can be adversely affected by reductions in resident wildlife, whether these reductions are caused by climate or other factors.

Various studies of the physical impacts of global warming have identified a rise in sea level, a decrease of inland lake levels, shrinkage of lake areas, retreat of mountain glaciers, and a loss of snow cover (Lino Grima, 1993; ACIA, 2004; Kaser et al., 2004; Smith et al., 2005). The impact of climate change on Alaska's natural environment is significant. The vast majority of glaciers in Alaska are retreating (ACIA, 2005). Summer sea ice off the Alaska coast has diminished dramatically since 1979 (Stroeve et al., 2007) and has thinned by $40 \%$ since the 1960 s. Many populations of marine mammals, fish, and seabirds have been reduced or displaced. These indirect impacts of climate change on natural resources have the potential to change the attractiveness of tourism destinations and to force a relocation of popular tourism destinations.

The direct effects of climate change on tourism arise from the fact that a destination's climate is an aggregate of the weather experienced by tourists. In this respect, climate directly affects demand for tourism and tourists' behavior and expenditures. Atmospheric conditions influence travelers' decisions about participating in an activity, as well as the quality of their experience. Nature-based tourism activities generally occur outdoors and can be precluded by rain, wind, fog, or other weather conditions. For example, tourism operators in Southeast Alaska noted a marked difference between the sunny, dry summer of 2004 and the cool, wet summers of 2006 and 2008. Revenues in 2006 were reduced because visitors were less likely to go on marine tours or hike in soggy conditions after they left their cruise ship (Colt et al., 2007).

Weather and climate play an important role in destination selection because tourists are sensitive to climate and to climate change (Maddison, 2001; Hamilton and Lau, 2005; Bigano et al., 2006a). Climate is an important component in a destination's image (Lohmann and Kaim, 1999). While it may not be the primary reason for selecting destinations, climate influences tourists' decisions on where and when to go (Giles and Perry, 1998). Hamilton and Lau (2005) confirmed that climate is at least the third most common attribute in tourists' decision making. Hence, climate and its changes are likely to influence tourists' decisions on selecting a destination and participating in tourism activities, as well as tourism demand and seasonality (Lise and Tol, 2002; Scott et al., 2004, 2007; Higham and Hall, 2005; Jones and Scott, 2006).

The impact of climate change on tourism demand has been quantified in several recent studies. Lise and Tol (2002) conducted a cross-sectoral analysis to estimate the relationship between international tourist arrivals and climate variables (temperature, precipitation), controlling for other explanatory variables such as price, trend, population density, length of coast, and area of the country. Using 17 years of data (1980-96) from 210 countries, this study suggested that there is an optimal average summer temperature (about $21^{\circ} \mathrm{C}$ ) for tourism and concluded that climate change probably does not affect global tourism demand. Instead the authors surmise that climate change causes a redistribution of tourists among destinations. Amelung and Viner (2006) suggest that if current climate projections prove correct, popular destinations in the Mediterranean will be less attractive in the 2050s because the summer climate will be too hot. Scott et al. (2007), who modeled the direct impact of climate change on visitations to Canada's Waterton Lakes National Park using data from 1996 to 2003, show a significant positive relationship between monthly visitation and minimum temperature. Their model projects that annual visitation would increase $6-10 \%$ by the 2020 s, $10-36 \%$ by the $2050 \mathrm{~s}$, and ultimately $11-60 \%$ over current baseline conditions under different climate change scenarios. Bigano et al.'s (2006b) general equilibrium model shows that climate change would shift patterns of tourism towards high latitudes and altitudes. Domestic tourism may double in colder countries and fall by $20 \%$ in warmer countries relative to the baseline without climate change. International tourism may treble in some countries, while it may be cut in half in others.

In other studies of tourism redistribution that could arise from climate change, Scott et al. (2004) and Amelung et al. (2007) applied comfort indices to measure the potential impacts of global warming on the attractiveness of a destination in terms of climate assets. These analyses found that a substantial spatial and temporal redistribution of climate resources for tourism was possible as a result of projected climate change in the 21st century. Already, recent climate change is affecting many ski resorts, especially 
those in lower altitudes. These resorts face economic hardship (Koenig and Abegg, 1997; Scott et al., 2006) to the extent that the Organization for Economic Co-operation and Development (OECD) warns that "Climate change is threatening Europe's skiing trade." Germany is most at risk among those countries studied "with the $1{ }^{\circ} \mathrm{C}$ warming scenario leading to a $60 \%$ decrease in the number of naturally snow-reliable ski areas" (OECD, 2006). Results from a snow-cover simulation model show that $2^{\circ} \mathrm{C}$ warming in the alpine region of Austria will cause a nearly 50\% reduction of the old snow cover and a higher reduction of the number of skiing days (Breiling and Charamza, 1999). The lower Laurentian Mountains of Québec are projected to experience a $40 \%$ to $89 \%$ reduction in season length (McBoyle and Wall, 1992), and the skiing season in central Ontario could be shortened by $40 \%$ to $100 \%$, and possibly eliminated at some locations. A general trend toward earlier spring snowmelt over Arctic terrestrial regions is already detectable (Foster et al., 2008).

An important direct impact of climate on tourism is tourism seasonality. Seasonality is one of the most representative attributes of tourism, and the vast majority of tourism destinations are characterized by systematic fluctuations of visitation (Kennedy, 1999; Baum and Lundtorp, 2001; Lim and McAleer, 2001). The seasonal pattern varies with the location of the destination as well as tourism activity (Ahas et al., 2007). For example, in the northern regions, the seasonal pattern generally exhibits a dramatic tourism peak in summer seasons (Jones and Scott, 2006) while in southern regions such as Florida, the peak periods occur during winter as well as summer (Braun and Rungeling, 1992). Coastal areas are usually popular summer tourism areas for beach-related activity, while mountain areas are popular in summer for hiking and sightseeing, as well as in winter for skiing (Ahas et al., 2007). When focusing on activities with a limited operating period, whether winter or summer, tourism businesses must make their profits during that restricted time. Hence, changes in patterns of seasonality due to climate change are economically significant. Improved understanding and anticipation of such changes would help tourist destinations, as well as other tourism industry sectors such as airlines and hotels, to plan and allocate resources more efficiently.

Changes in seasonality can create new opportunities as well as new constraints for tourism-related outdoor recreation (Scott et al., 2005, 2007; Becken and Hay, 2007; UNWTO, 2007). For example, while low-altitude ski resorts face economic challenges due to less snowfall and shorter skiing seasons, Arctic regions will stand to gain, as their summer season is likely to lengthen (Pagnan, 2003). Possible impacts of future climate change on seasonal patterns of tourism for general summer tourism activity have been examined for some countries such as Canada, where the warm-weather tourism season will be substantially longer in the late 21st century under various climate-change scenarios (Scott et al., 2004, 2007). The seasonal tourism pattern in the Mediterranean is likely to shift from the current summer peak to a "double shoulder" (spring and fall) pattern (Amelung and Viner, 2006).

Tourism in Alaska is highly seasonal. Summer (June, July, and August) is the main season for visitation. However, abundant evidence suggests that Alaska is warming, most noticeably in the winter and spring. Alaska has warmed (on average) by $2^{\circ} \mathrm{C}\left(4^{\circ} \mathrm{F}\right)$ since the $1950 \mathrm{~s}$, with the largest increase of about $4^{\circ}$ to $5^{\circ} \mathrm{C}\left(8^{\circ} \mathrm{F}\right)$ in the Interior during the winter (Alaska Climate Research Center, 2009). This warming can affect the timing of seasonal activities and is already being felt by indigenous communities and by various industry sectors (Alaska Native Science Commission, 2005). Gregory et al. (2006) report that climate changes in northwest Alaska significantly affect the timing of resource availability (fishing, hunting) and access to resources such as ice, rivers, and the ocean.

This study extends the literature on impacts of climate, particularly its seasonality, by using Alaska as a case study for 1) adopting an hourly tourism climate index to assess the variability of favorable conditions for specific tourism activities (i.e., summer outdoor activities and winter skiing) and 2) presenting a method of quantifying the seasonal patterns and their variations. Despite the overwhelming evidence that significant seasonal climate changes are occurring in Alaska, and the recognition that these climate changes are bound to affect tourism (ACIA, 2005), research addressing the climate change and tourism domain in Alaska is scarce. This paper attempts to quantify the impact of climate change on the seasonal patterns of tourism opportunities in Alaska over multi-decadal timescales.

More generally, the purpose of this study is to devise and test a quantitative tool for measuring climate as a tourism resource. In this respect, the study is a step toward needed quantification of the very general statements in recent climate impact assessment reports that tourism is likely to be impacted by climate change (e.g., ACIA, 2005:1003; IPCC, 2007). The method presented here uses multivariate information at high temporal resolution, thereby bridging the gap between weather that tourists actually experience and the climate information that is generally represented by averages.

\section{METHODS AND DATA}

\section{A Weather-Based Climate Index for Tourism}

Climate indices have been frequently used to assess the suitability of climate for tourism (Mieczkowski, 1985; de Freitas et al., 2004). Both Scott et al. (2004) and Amelung et al. (2007) applied Mieczkowski's (1985) tourism climate index to assess the impact of climate change on the seasonal pattern of ideal climate conditions for tourism in various regions. These studies were conducted at a macro-scale and are relevant to general tourism activity.

The present study adopts a three-level Modified Climate Index for Tourism (MCIT) suggested by Yu et al. (2009). 
Improving on Mieczkowski's (1985) index, the recently modified index 1) combines weather elements that are more relevant to tourism, and 2) addresses the overriding nature of individual weather elements (instead of arbitrarily assigning weights). By "overriding nature," we mean that the aggregated index is characterized as unsuitable for a particular tourist activity if even one of its components is in the unsuitable category. The MCIT integrates multiple weather elements (see below) that affect the quality and suitability of weather conditions for outdoor tourism (Matzarakis and Moya, 2002).

A prominent feature of this index is the use of hourly weather observations. Hourly data contain more valuable information than statistical data (such as averages, maxima, and minima) because the hourly variation of weather elements such as rain, thunderstorms, and visibility is closely related to the viability of outdoor tourism activities at the individual destination level and cannot be ignored. For example, consider a day with total precipitation of $1 \mathrm{~cm}$. This " $1 \mathrm{~cm}$ " could be the result of a one-hour intense downpour, or 12 hours of lighter rain. It could occur during midday or at midnight. These different possibilities have very different implications for the viability of outdoor recreation that usually takes place during daytime. Hence, a day that is categorized as "unsuitable" using daily summary data could in fact be a nice day for outdoor recreation and vice versa. Furthermore, the use of hourly data provides greater opportunity to address the specific relevance to different tourism activities (e.g., weather conditions suitable for playing golf are not necessarily the best for bird watching, fishing, or hunting). Obviously, differences in weather conditions between summer activities such as sightseeing and winter activities such as downhill skiing are even more substantial. An hourly index can be tailored to measure the suitability for a specific tourism activity that requires particular weather conditions during a particular portion of the day. It can provide micro-level information on the number and seasonal patterns of days or hours suitable for a specific tourism activity at a particular destination in an area with specific natural resources (e.g., beach or mountains). It can capture, through frequency statistics such as those presented here, the probabilities that particular hours (or subsets of hours) of a calendar day, week, or month will be suitable for a particular outdoor activity - a level of detail that cannot be obtained from monthly or even daily data. User-specified selection of a subset of the 24-hour diurnal cycle also obviates the need for weighting of different hours of the day (no such weighting is employed in this study). In summary, sub-daily information based on specific user requirements can be considerably more valuable to tourism managers and planners than daily and especially monthly averaged data.

A key issue in the construction of a weather-based climate index for tourism is the selection of weather variables. Smith (1993) and Matzarakis (2001) suggest that the weather parameters affecting tourists' comfort and safety include air temperature, humidity, radiation intensity, wind speed and direction, cloud cover, sunshine duration, and precipitation. De Freitas (2003) classifies climate according to its thermal, physical, and aesthetic aspects. The thermal aspect incorporates air temperature, humidity, wind, and solar radiation; the physical aspect includes rain and wind; and the aesthetic aspect relates to sunshine or cloud conditions. Hamilton and Lau (2005) found that while temperature is a dominant attribute, $91 \%$ of the respondents indicated that more than one tourism-related climate attribute is significant. De Freitas et al. (2004) showed that within a broad range of "non extreme" thermal conditions, several different factors are important in determining the pleasantness rating of given climate conditions. For example, the nonthermal elements of rain, high wind, and low visibility have considerable impact on tourists' satisfaction.

In view of the above literature and the availability of weather variables in historical weather archives, we base our index on four weather components: perceived temperature, wind, visibility, and significant weather. Perceived temperature combines temperature, relative humidity, and wind. It is represented by the Wind Chill Index in the winter (when temperatures are below $10^{\circ} \mathrm{C}$ or $50^{\circ} \mathrm{F}$ ) and by the Heat Index during the summer (Rauber et al., 2008). Low or high perceived temperatures are uncomfortable and can be harmful to tourists. High wind and low visibility can considerably degrade tourist satisfaction and affect outdoor safety. Significant weather, which is coded from 0 to 99 in standard weather reports (Present Weather Code Table, 2005), encompasses different weather conditions such as snow, rain, lighting, fog, smoke, and dust storms.

A sub-index is created for each of these four weather components $\mathrm{MCIT}_{\mathrm{xx}}$, in which the subscript $\mathrm{xx}$ can represent $\mathrm{PT}=$ Perceived Temperature, $\mathrm{W}=$ wind, $\mathrm{V}=$ Visibility, or SW = Significant Weather). Each sub-index is scaled to three levels of suitability for outdoor tourism activities $(0=$ unsuitable conditions, $1=$ marginal conditions, and 2 = ideal conditions) indicated by upper and lower thresholds. For example, the $\mathrm{MCIT}_{\mathrm{v}}$ is 2 if visibility is greater than $4.0 \mathrm{~km}$, while MCIT $_{\mathrm{Sw}}$ is 0 if significant weather events are likely to hamper outdoor activities. The thresholds and sub-index categories are summarized in Table 1. The criteria used to scale the sub-indices are flexible and can be modified to best fit the characteristics and requirements of specific activities. In practice, these activityspecific thresholds could be determined by industry experts or from surveys of tourists. We stress that the thresholds and cutoffs can be modified to fit any activities for which a user can provide reasonable weather-related thresholds for tourist involvement.

The four sub-indices are then used to form an aggregated index (MCIT). To account for the overriding nature of these weather elements, MCIT is structured as the product of four sub-indices with equation (1). The MCIT ranges from 0 to 2 , where 0 denotes unsuitable conditions for tourism, 1 denotes marginal conditions, and 2 denotes ideal conditions. MCIT is 0 when any of the four sub-indices is 0 , and is 2 only when all four sub-indices are 2 . 


$$
\begin{aligned}
& \text { MCIT }=0 \text { if } \prod_{x x} M C I T_{x x}=0 \\
& \text { MCIT }=1 \text { if } 0<\prod_{x x} M C I T_{x x}<16 \\
& \text { MCIT }=2 \text { if } \prod_{x x} M C I T_{x x}=16
\end{aligned}
$$

where $\Pi$ denotes the product of the four sub-indices $\mathrm{MCIT}_{\mathrm{xx}}$ (for perceived temperature, wind, visibility, and significant weather).

\section{Applications of the MCIT}

This hourly index can be used in a wide range of tourism-related climate applications. The annual, monthly, and hourly occurrence frequencies of certain MCIT (and $\mathrm{MCIT}_{\mathrm{xx}}$ ) values can be used to examine the overall quality of the destination's climate resources, to identify seasonal and daily patterns of variation, and to explore the impact of climate change on climate resources for tourism by examining the change of each weather or climate element over time. A daily tourism weather index is likely to outperform a climatological average measure when more weather constraints must be considered (e.g., the minimum number of consecutive hours of ideal weather condition, or the precise length of a tourist "season"). Finally, the design of the MCIT as summarized above allows us to determine which weather element is a main obstacle or contributor to the overall suitability of a location's climate for tourism activities. The following subsections demonstrate how various integrated measures of tourism suitability are derived from the hourly MCIT index and sub-indices. Some examples of statistical analyses are also provided.

\section{Seasonal Patterns}

Most previous studies have examined seasonality using monthly data. This study attempts to quantify the seasonal pattern at finer timescales to capture potential changes in the activity periods (e.g., the start and the end of the season) that are difficult to see in the monthly data. The quantification of the seasonal pattern, which includes the start date, end date, and quality of the season, is based on the daily frequency for ideal weather condition calculated using the hourly MCIT, as follows:

$$
\begin{gathered}
F_{i y}=\sum_{h=h_{1}}^{h_{2}} N C I T_{i y h} /\left(h_{2}-h_{1}+1-q_{i y}\right) \mathrm{i}=1, \ldots, 365, \mathrm{y}=\mathrm{y}_{1}, \ldots, \mathrm{y}_{2} \\
N C I T_{i y h}=1 \text { when } \operatorname{MCIT}_{i y h}=2 \\
N C I T_{i y h}=0 \text { when } \operatorname{MCIT}_{i y h}<2
\end{gathered}
$$

where $F_{i y}$ denotes the frequency of ideal conditions in the $\mathrm{i}^{\text {th }}$ day of year $\mathrm{y}, y_{1}$ and $y_{2}$ denote the start year and the end year of the study period, respectively, and $q_{\mathrm{iy}}$ denotes the number of hours in which data are missing during time period $h_{1}$ to $h_{2}$ in the $\mathrm{i}^{\text {th }}$ day of year y. The range of $h$ (from $h_{1}$ to $h_{2}$ ) can be specified to include the entire 24 hours $\left(h_{1}=1, h_{2}=24\right)$ or a subset of the day (for example, $h_{1}=8, h_{2}=20$ ).

In order to identify the start and end dates of a season suitable for a particular tourism activity, it is desirable to reduce the noise caused by short-term weather variations. For this purpose, the daily frequency distribution for each year is smoothed with an odd $p$-point filter (e.g., $p=7,9,11$ ) as follows:

$$
\bar{F}_{i}=\left(F_{i-\frac{p-1}{2}}+\ldots+F_{i-1}+F_{i}+F_{i+1}+\ldots+F_{i+\frac{p-1}{2}}\right) / p \mathrm{i}=1, \ldots, 365
$$

where $F_{i}$ denotes the frequency of ideal conditions (MCIT = 2 ) on the $\mathrm{i}^{\text {th }}$ day of a year and $F_{i}$ is the smoothed frequency of $F_{i}$ after the application of (3). The value of $\mathrm{i}=1$ on 1 January for activities with a summer peak, while $i=1$ on 1 July for activities with a winter peak.

The shape of the smoothed seasonal pattern is affected by the width of the smoothing window, $p$. A small $p$ results in a noisier curve, while a large $p$ produces a smoother pattern. Since particular weather systems (e.g., high and low pressure centers, waves in the jet stream aloft) generally affect a location for periods of several days to several weeks, values of $p$ ranging from 7 to 28 (in increments of 7) were used to test the sensitivity of the smoothed pattern to the value of $p$. Values of $p=7$ and 14 left considerable noise in the patterns, while $p=28$ had a noticeable impact on the seasonal amplitudes, i.e., it reduced the maxima and increased the minima. Consequently, a value of $p=21$ was used to produce the seasonal patterns plotted in the next section.

Given a smoothed seasonal pattern, several metrics can be extracted to characterize the pattern. Examples include the start and end days of the season, and the quality of the season. The "start day" and "end day" of the season are determined using a prescribed threshold $c$. A "start day" of a season is defined as the first date on which the smoothed frequency is equal to or larger than a certain threshold value (e.g., $c=0.30,0.35$, or 0.40 ). An "end day" is defined as the last date on which the smoothed frequency is equal to or larger than that threshold. For example, a threshold of $c=$ 0.30 implies that, over the period of many years, a minimum of $30 \%$ of the hours must be in the "ideal" category if a calendar date is to be considered part of the season for a particular tourism activity. The prescribed value of $c$ will affect the value of the start day and the end day of a year. The season starts earlier and ends later when $c$ is smaller than when $c$ is larger. However, we are more concerned with the changes or trends over time of the start and end days. Since favorable weather during 4-6 hours, representing 30-40\% of the 6:00 a.m. to 9:00 p.m. "tourism day," is a reasonable requirement or expectation for participation in an outdoor tourism activity, we used values of $c=0.3,0.35$, and 0.4 to test whether the change (trend) of the start day and the end day is affected by different values of the threshold. The results showed that the change (trend) of the "start day" and "end day" over time is nearly identical whether $c$ 
$=0.3,0.35$, or 0.4 . In view of this weak dependence of temporal variations on the value of $c$, a threshold of $c=0.35$ is applied in this paper.

In addition to the start day and the end day, we used three variables - the average frequency of ideal conditions during the main season, spring, and fall - to quantify season quality. The main season is June through August for a summer activity, December through February for a winter activity. Spring and fall are considered transition seasons.

\section{Statistical Analysis}

To further examine the impact of climate change on the seasonal patterns, we analyzed these patterns in terms of the statistically most common types of seasons. The statistical tool was cluster analysis. Specifically, K-means clustering was conducted to identify the types of seasonal patterns. K-means clustering is a technique used to discover "natural" groupings in a set of patterns, points, or objects without prior knowledge of the number of clusters or any other information about their composition (Anderson et al., 1998). It first partitions the objects into a pre-estimated number of groups and then iteratively reallocates objects to clusters until some criterion is met (e.g., minimization of within-cluster variance). Ultimately, seasonal patterns with similar features (e.g., early start day, late end day, and high quality of the season) are in one cluster and seasonal patterns with other features (e.g., late start day, early end day, and low quality of the season) are in another cluster. Each cluster is characterized by a centroid pattern. The determination of the optimal number of patterns is discussed in the following section.

In addition, linear regression models were fitted to assess the significance of the observed trends and changes over time. The dependent variables were the start day and end day of the season, annual frequency, and seasonal frequency. Time (year) was the independent variable. Correlation analysis was conducted to explore the relationship between the changes in seasonal pattern and temperature.

\section{Data}

Hourly weather observations from two destinations in Alaska, King Salmon (1943-2005) and Anchorage (19422005), were used in this study. Summer sightseeing and fishing are the main tourism attractions in King Salmon, which is located a short distance from Katmai National Park, a renowned area for viewing bears and other wildlife (Fig. 1). Anchorage is the most popular area for skiing in Alaska. The city's wealth of cross-country ski trails gives it a higher concentration of urban skiers than any other city in the United States, and several major downhill ski areas nearby (e.g., Alyeska at Girdwood) attract local as well as out-of-state skiers. King Salmon's summer season length was quantified using hourly values of the MCIT that were based on thresholds specified to capture suitability of weather conditions for sightseeing (Table 1). Anchorage's winter season length was quantified using MCIT values based on thresholds specified to capture suitability for skiing (Table 1).

\section{RESULTS}

\section{Seasonal Patterns}

The ideal weather conditions for both sightseeing and skiing exhibit unambiguous seasonal patterns. Figure 2 shows the seasonal patterns in a traditional way, using the monthly average frequency of ideal conditions $(\mathrm{MCIT}=2)$. The frequency of ideal weather conditions for sightseeing in King Salmon peaks in the summer season, and conversely, the frequency of ideal conditions for skiing in Anchorage peaks in the winter. Figures 3 and 4 display the average conditions for the study period shown in Figure 2, but using daily rather than monthly averages. In addition, they add the average daily conditions for two individual years, 1956 and 2005 for sightseeing at King Salmon and 1971 and 1992 for skiing at Anchorage. The more detailed information in these daily time series allows for an in-depth analysis of shifts in seasonal patterns over time. Figures 3 and 4 illustrate that the start and end dates of both sightseeing and skiing seasons, as well as the quality of the season, can vary considerably among years.

Within the 365-day cycles of frequencies we tracked six variables, two for length and four for quality, of the sightseeing season in King Salmon and the skiing season in Fairbanks:

1) start day

2) end day

Frequency of ideal conditions for:

3) entire year

4) transition to main season

5) main season

6) transition from main season.

The cluster analysis, performed on the 63 yearly cycles of values of these six variables for each site, produced a set of four primary anomaly patterns for each location that collectively capture the largest portion of the interannual variance. The determination of the number, $\mathrm{K}$, of clusters is one of the main challenges of cluster analysis. Much research has been done to find an effective way for determining the optimal K (e.g., Fraley and Raftery, 1998; Dudoit and Fridlyand, 2002). However, there are still no universally accepted methods for determining the number of clusters for any type of cluster analysis (Bock, 1985; Pelleg and Moore, 2000). We performed multiple trials with different numbers of clusters ( $\mathrm{K}=2,3,4$, and 5$)$ and employed the commonly used cubic clustering criterion (CCC) as a metric. A larger $\mathrm{CCC}$ indicates a more distinct set of clusters 


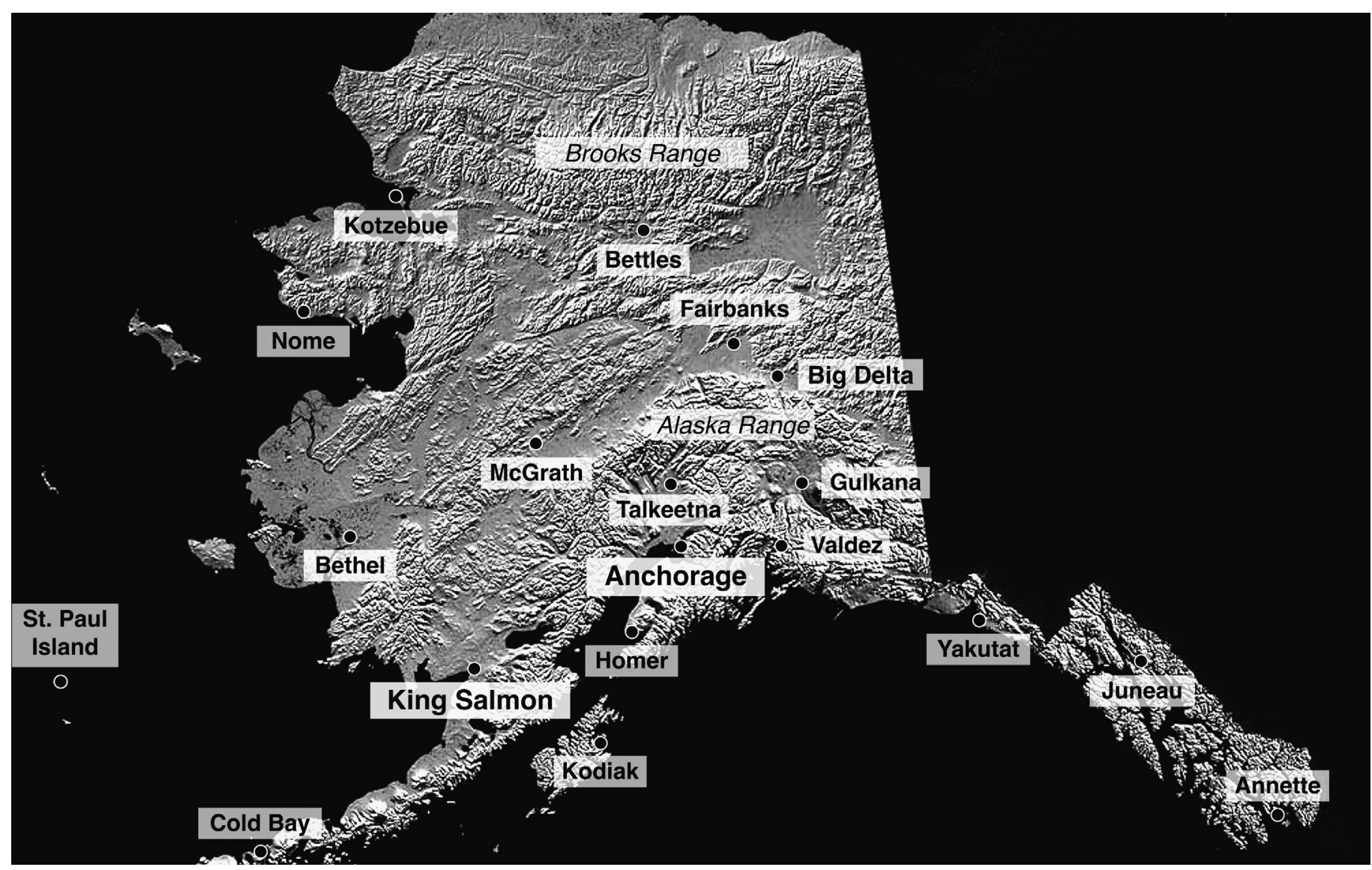

FIG. 1. Map of Alaska, showing the Anchorage and King Salmon tourist areas used in the study and other major locations.

TABLE 1. Scaling criteria for Modified Climate Index for Tourism (MCIT) sub-index values for perceived temperature (PT), wind (W), Visibility (V), and Significant (Present) Weather (SW).

\begin{tabular}{|c|c|c|c|c|c|}
\hline \multirow[b]{2}{*}{ Conditions } & \multicolumn{2}{|c|}{ Perceived Temperature $\left({ }^{\circ} \mathrm{F}\right)$} & \multirow[b]{2}{*}{ Wind (mph) } & \multirow[b]{2}{*}{ Visibility $(\mathrm{km})$} & \multirow[b]{2}{*}{ Present Weather ${ }^{1}$} \\
\hline & Sightseeing & Skiing & & & \\
\hline 0 (Unsuitable) & $<20$ or $>95$ & $<-20$ or $>40$ & $>20$ & $<1$ & $\begin{array}{l}9,17,19,25,26,27,28,29,32,35,36,37,38,39,46,47, \\
>51 \text { and }<100\end{array}$ \\
\hline 1 (Marginal) & $20-40$ or $85-95$ & $-20--40$ or $32-40$ & $13-20$ & $1-4$ & $\begin{array}{l}6,7,8,15,16,18,20,21,22,23,24,30,31,33,34,40 \\
41,42,43,44,45,48,49,50,51\end{array}$ \\
\hline 2 (Ideal) & $40-85$ & $-10-32$ & $<13$ & $>4$ & $0,1,2,3,4,5,6,10,11,12,13,14$ \\
\hline
\end{tabular}

${ }^{1}$ Weather condition codes in column 6 are from the Present Weather Code Table (2005).

(SARLE, 1983). The CCC values were 1.27, 1.59, 3.16, and 2.63 for $\mathrm{K}=2,3,4$, and 5, respectively, in the King Salmon case, and $3.55,6.68,7.66$, and 6.18 for $\mathrm{K}=2,3,4$, and 5 in the Anchorage case. Thus the tests showed that $\mathrm{K}=4$ is the optimal number of clusters for both sightseeing season patterns at King Salmon and skiing season patterns at Anchorage.

The following section describes the seasonal patterns, examines their temporal variations, and discusses other issues that emerged as a result of the categorization. To the extent that patterns in past years can be associated with particular impacts, knowledge of future changes in these patterns will aid planners and decision makers in allocating tourism resources.

\section{Types of Seasonal Patterns}

The Appendix lists the clusters obtained using the six variables described above for the years 1943-2005. All four patterns of sightseeing for King Salmon display a summer peak with variation in season quality and start and end days. As shown in Figure 5, the four patterns at King Salmon can be characterized in terms of season length and Frequency of Ideal Conditions (FoIC) as follows:

1) Low annual and summer FoIC, late start of the season;

2) Low annual and summer FoIC, early start and early end of the season;

3) High annual and summer FoIC, and early start of the season; 


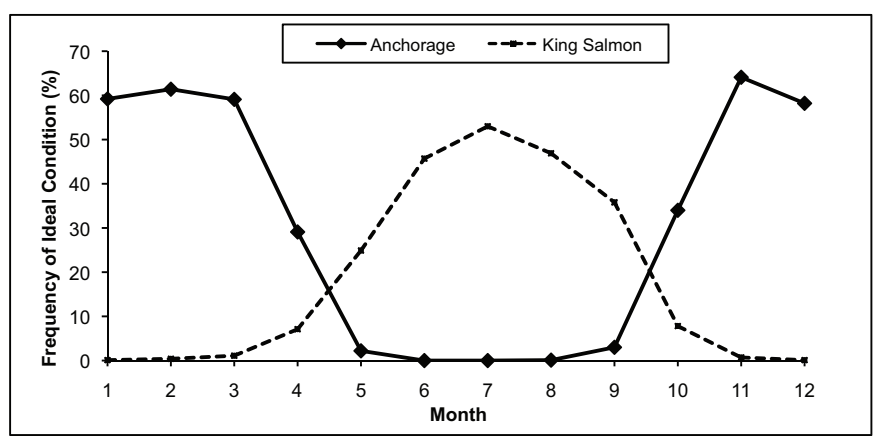

FIG. 2. Mean monthly percentages of ideal conditions $(\mathrm{MCIT}=2)$ for King Salmon sightseeing and Anchorage skiing, 1943-2005.

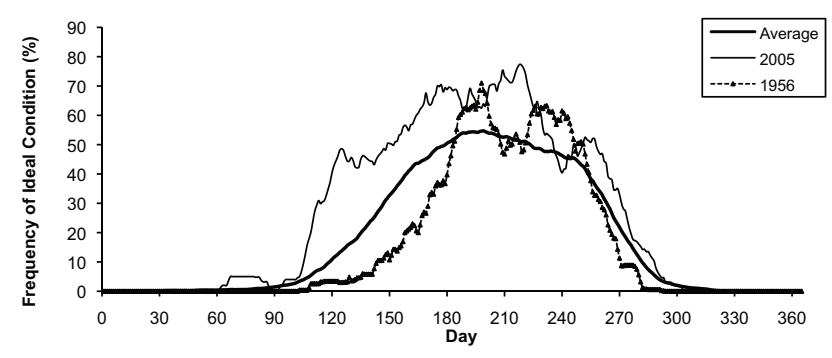

FIG. 3. Year-round daily percentages of ideal conditions for sightseeing at King Salmon (1943-2005 average, 1956, and 2005). Day 1 is 01 January.

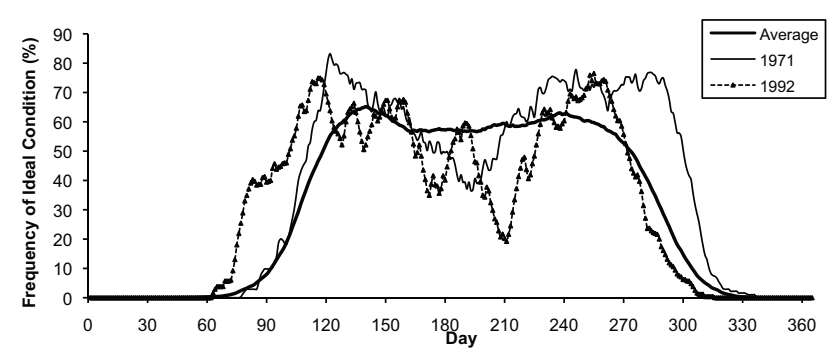

FIG. 4. Year-round daily percentages of ideal conditions for skiing at Anchorage (1943-2005 average, 1971, 1992). Day 1 is 01 July.

4) Moderately high annual and summer FoIC, and late end of the season.

Both the Type 1 and Type 2 patterns have a low annual frequency of ideal conditions caused by low summer frequency, and either a late start (Type 1) or an early end (Type 2) of the season (Fig. 5). Types 3 and 4 contain high annual frequencies of ideal conditions caused by the high frequency of ideal conditions in the summer, as well as an early start and a late end. Both the seasonal length and the quality of pattern Type 3 are more favorable than those of pattern Type 4.

Unlike King Salmon's sightseeing pattern, which is characterized by a broad summer peak in all clusters, the skiing patterns in Anchorage can be classified into two general categories: a shoulder pattern (a dip around January) with two peaks occurring around November and February, and a one-peak pattern (relatively equal quality through the whole season). However, two clusters emerge within each larger

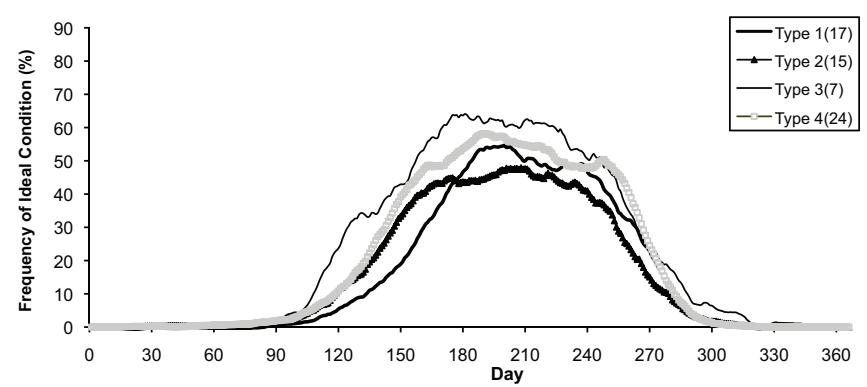

FIG. 5. Daily percentages of ideal sightseeing conditions at King Salmon for each of the four clusters (types) of seasonal-cycles. Day 1 is 01 January. Parentheses in the legend show number of years corresponding to each seasonal cycle type.

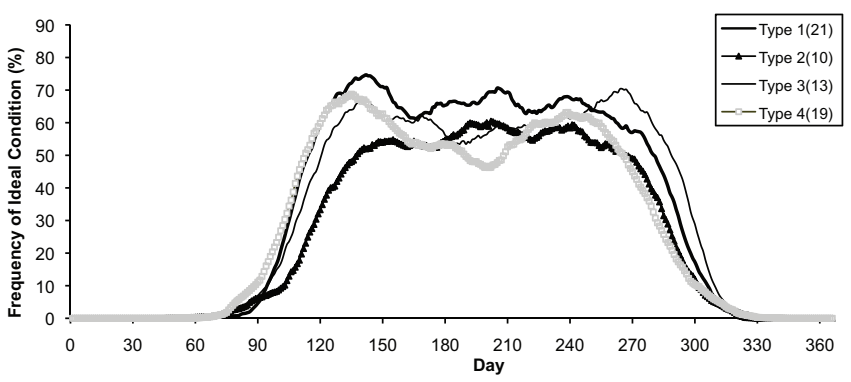

FIG. 6. Daily percentages of ideal skiing conditions at Anchorage for each of the four clusters (types) of seasonal-cycles. Day 1 is 01 July. Parentheses in the legend show number of years corresponding to each seasonal cycle type.

category. Therefore, the 63 seasons of skiing are again classified into four patterns, characterized as follows:

1) High annual, fall, winter, and spring FoIC, early start and late end of the season;

2) Low annual, fall, and spring FoIC, late start and early end of the season;

3) High spring FoIC, late end of the season;

4) High fall FoIC, low winter and spring FoIC, early start of the season.

Figure 6 displays the average FoIC distribution of each season type for Anchorage. While Type 1 and Type 2 share the similar single-peak pattern, the distinction between them is obvious. Type 1 is characterized by a high annual frequency of ideal conditions, which is mainly due to the high FoIC during the entire fall, winter, and spring, and slightly earlier start and later end of the season. By contrast, the Type 2 pattern is characterized by a low annual frequency caused by low FoIC during both fall and spring, relatively high winter FoIC, and an early end of the season. The primary difference between Types 3 and 4 is that Type 3 starts late and ends late with a relatively high FoIC in fall, but Type 4 starts earlier and ends earlier with relatively high FoIC in spring.

Cluster-average values (expressed as departures from the all-year means) of the six key variables are presented in Table 2 for each of the four clusters for King Salmon and Anchorage. 
TABLE 2. Cluster centers (values of anomalies averaged over years in cluster) for seasonal patterns and number of years in each cluster.

\begin{tabular}{|c|c|c|c|c|c|c|c|c|c|c|c|}
\hline \multicolumn{6}{|c|}{ King Salmon (Sightseeing) } & \multicolumn{6}{|c|}{ Anchorage (Skiing) } \\
\hline \multirow[b]{2}{*}{ Attributes } & & \multicolumn{4}{|c|}{ Cluster (pattern type) } & & & \multicolumn{4}{|c|}{ Cluster (pattern type) } \\
\hline & & 1 & 2 & 3 & 4 & Attributes & & 1 & 2 & 3 & 4 \\
\hline \multirow[t]{4}{*}{ FoIC } & Annual & -2.16 & -2.09 & 4.87 & 1.43 & FoIC & Annual & 3.84 & -3.25 & -2.78 & -.62 \\
\hline & Spring & -6.29 & -.01 & 9.53 & 1.68 & & Fall & 5.14 & -16.09 & -5.64 & 6.64 \\
\hline & Summer & -3.61 & -5.05 & 9.60 & 2.92 & & Winter & 6.29 & 2.67 & -7.76 & -3.07 \\
\hline & Fall & -1.26 & -8.12 & 2.96 & 5.10 & & Spring & 8.48 & -6.52 & 0.98 & -6.62 \\
\hline Start day & & 17.17 & -.10 & -26.59 & -4.34 & Start day & & -2.90 & 14.90 & 6.41 & -9.06 \\
\hline End day & & 1.48 & -13.23 & 1.73 & 6.72 & End day & & 7.78 & -6.80 & 5.38 & -8.81 \\
\hline Number of years & & 17 & 15 & 7 & 24 & Number of years & & 19 & 10 & 13 & 21 \\
\hline
\end{tabular}

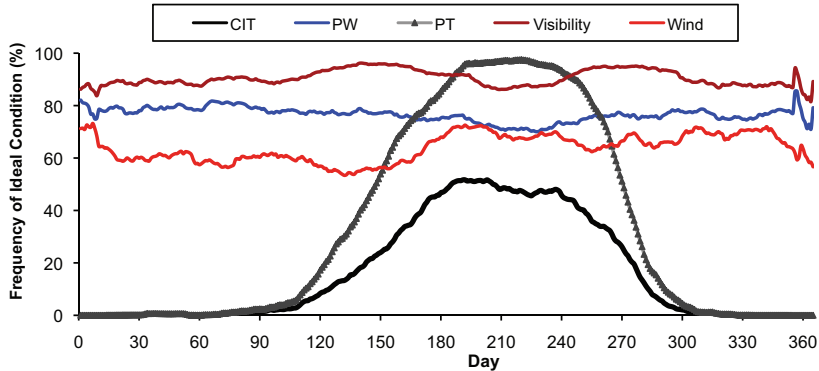

FIG. 7. Frequency of occurrence in seasonal pattern Type 1 of ideal King Salmon sightseeing conditions (value $=2$ ), showing total MCIT and the four sub-indices, perceived temperature PT, wind W, visibility V, and significant weather SW.

\section{Weather Elements Affecting MCIT Patterns}

To understand which weather elements drive these patterns, we compared the seasonal cycle of average FoIC of each sub-index (PT, W, V, and SW) for the years in each cluster to the average frequency patterns of the MCIT for those years. Not surprisingly, the results show that the FoIC of Perceived Temperature (PT) exhibits a seasonal pattern similar to that of MCIT for both the sightseeing and skiing activities, implying that perceived temperature is a main determinant of the MCIT pattern. However, the other weather elements also contribute to season quality. An example is provided in Figure 7 for King Salmon's Type 1 pattern. Although the FoIC of PT is very high, over $90 \%$ during the summer peak season, the FoIC values for the combined MCIT are only about $40 \%$ when the impacts of other weather elements are included. Wind and present weather (e.g., rain, thunderstorms) are important factors that also affect MCIT of sightseeing at King Salmon (Fig. 7). This conclusion applies to all other pattern types of sightseeing in King Salmon.

Similarly, temperature is the main climate element that affects the MCIT of skiing in Anchorage. For example, Anchorage pattern Type 4 (Fig. 8) shows very similar seasonal patterns for FoIC of PT and the overall MCIT. Present weather, as well as temperature, affects the MCIT. Wind and visibility have less influence than temperature and present weather on the MCIT of skiing in Anchorage.

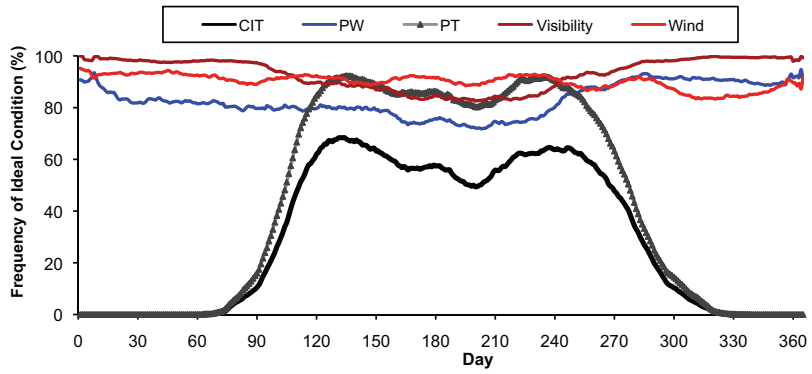

FIG. 8. Frequency of occurrence in seasonal pattern Type 4 of ideal Anchorage skiing conditions (value $=2$ ), showing total MCIT and the four sub-indices, perceived temperature PT, wind W, visibility V, and significant weather SW.

Figures 7 and 8 also highlight large differences between the two stations in the relationship between the FoICs of MCIT and PT during the main season. For example, during July and August at King Salmon, although the temperature component of the FoIC is ideal for sightseeing (over $95 \%$ ), the FoIC of the combined MCIT is only about $50 \%$ in pattern Type 1, implying that about half the opportunities are lost because of other weather elements. Future changes in temperature are less likely to affect the overall FoIC of sightseeing in King Salmon in summer than in other seasons (i.e., spring, fall). However, the situation for skiing in Anchorage is different. For the Type 4 pattern, there is a relative dip around December and January. This dip is mainly caused by the temperature, as the PT component has the same shape as the overall FoIC. Logically, this dip is caused by the increased frequency of very low temperatures rather than by high temperatures. Therefore, future changes in temperature are very likely to affect the frequency of occurrence of this pattern. For instance, if the present warming trend continues, this dip will become less common, resulting in a shift to increasing frequencies of Types 1 or 2 (winter peak).

In summary, the results show that while temperature is the main constraint in shaping the seasonal pattern of sightseeing and skiing, other weather elements also play important roles. The results also indicate that future climate change (i.e., continued warming) is very likely to extend the sightseeing season at King Salmon but is less likely to improve the quality of the peak season further. At the same time, warming is very likely to shorten the overall skiing 


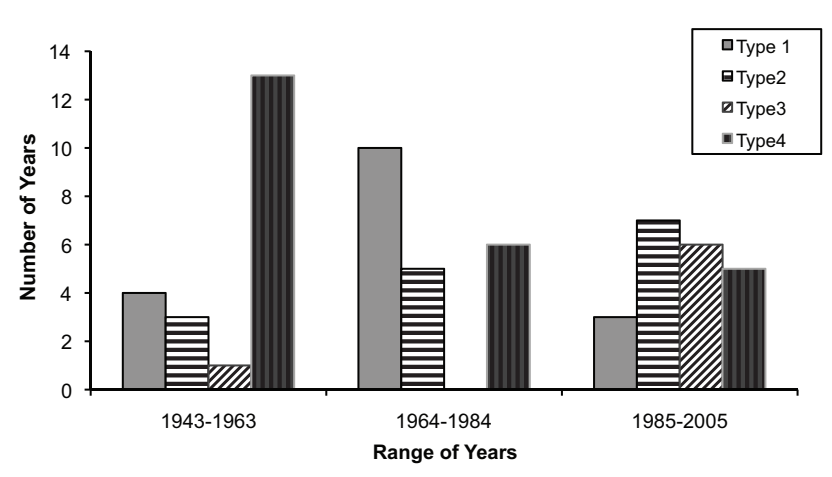

FIG. 9. Distribution of the four seasonal patterns of King Salmon sightseeing conditions over three 21-year time slices (1943-63, 1964-84, and 19852005).

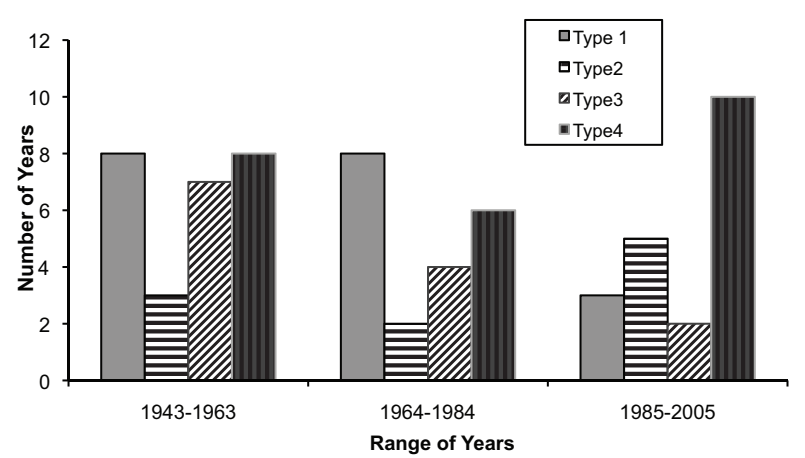

FIG. 10. Distribution of the four seasonal patterns of Anchorage skiing conditions over three 21-year time slices (1943-63, 1964-84, and 19852005).

season, but is also likely to improve its quality in winter and increase the frequency of years with mid-winter peaks of quality (FoIC). These projections have implications for planners concerned with maximizing the efficiency of the skiing industry in Alaska.

\section{Trend of Seasonal Patterns}

Visual examination of the seasonal pattern types for the different years (Appendix) shows that the four seasonal patterns obtained from the cluster analysis are not randomly distributed over time, but seem to exhibit some systematic variations. First, the same pattern often lasts for several consecutive years. In the case of King Salmon, for example, the Type 4 seasonal pattern predominated between 1943 and 1951, while Type 2 seasons occurred frequently between 1988 and 1994. Also note that recent years seem to be characterized by long sightseeing season patterns and short ski season patterns, consistent with the recent warming trends in spring and winter, as discussed below.

Figures 9 and 10 display the numbers of years in each pattern in three sub-periods of equal length. Figure 9 shows that nearly all occurrences of the sightseeing season pattern with greater length and higher FoIC (Type 3) have been in the recent decades (1985-2005), while patterns with moderately high annual and summer FoIC (Type 4) decreased

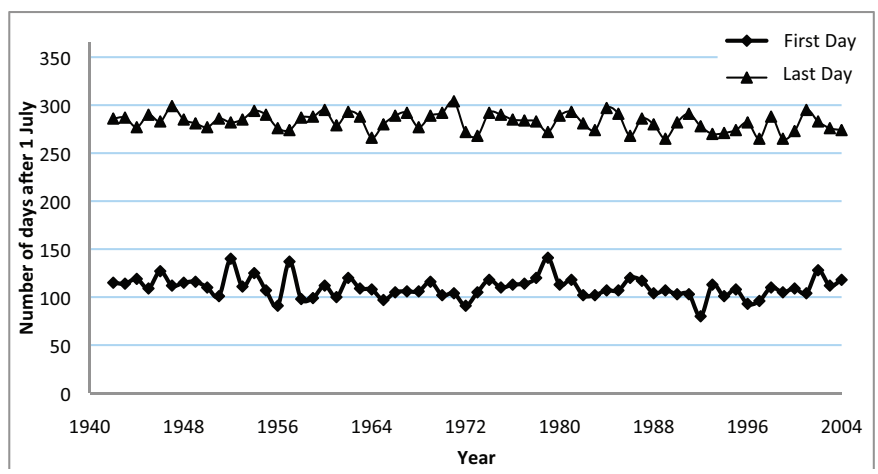

FIG. 11. Annual values (1943-2005) for the first day and last day of the Anchorage ski season. Values are based on a threshold frequency of $c=0.35$ and a daily smoothing parameter of $p=21$. Day $1=01$ July.

in frequency over time, implying an evolution from Type 4 to Type 3 . At the same time, the Type 1 pattern, which has a late start of the season, decreased dramatically from 1964-84 to $1985-2005$, while the Type 2 pattern, which has an early start of the season, increased over time. These changes indicate that the sightseeing season now tends to start earlier. Figure 10 shows that the frequencies of Anchorage's Types 1 and 3 decreased over time, while the frequencies of Types 2 and 4 increased over time, especially from $1964-84$ to $1985-2005$. These results imply not only that the overall quality of the skiing season in Anchorage has decreased, but also that the season tends to end earlier. In summary, the results show that the quality of the sightseeing season in King Salmon has been improved along with an earlier start, and the quality of the skiing season in Anchorage has decreased with an earlier end of the season.

Although the start day and end day of the sightseeing season at King Salmon showed little change from the 1940 s to the 1970 s, an apparent trend toward an earlier start day began in the $1980 \mathrm{~s}$, indicating that the earlier start of the sightseeing season is a fairly recent development. In the case of skiing in Anchorage, the season has shown not only interannual variability, but an earlier end day in recent years, while the start day of the season has shown little change (Fig. 11). These trends are generally consistent with temperature trends, which show an increase during spring but little change during autumn over much of southern Alaska (Alaska Climate Research Center, 2009).

To identify whether these trends are statistically significant, the start day and end day were linearly regressed onto time, i.e., year was the independent variable. The results (Table 3) confirm that the trend toward an earlier end of Anchorage's ski season since the 1940s is statistically significant. The earlier start of King Salmon's sightseeing season is not statistically significant over the entire period, but is statistically significant over the last three decades. The coefficients also indicate that compared to 60 years ago, the start date of the sightseeing season is now 10 days earlier, and the end date of the skiing season is now nine days later.

Table 3 also shows trends of the frequencies of ideal conditions. The increases in the FoIC for sightseeing in 
TABLE 3. Linear regressions of Frequency of Ideal Conditions (FoIC) for King Salmon sightseeing and Anchorage skiing vs time, showing coefficients of correlation for whole year, spring, summer, fall, start day, and end day.

\begin{tabular}{|c|c|c|c|c|c|c|c|}
\hline Station & Time Period & Annual & Spring & Summer & Fall & Start Day & End Day \\
\hline King Salmon (Sightseeing) & $1943-2005$ & $0.050^{*}$ & $0.098^{*}$ & $0.096^{*}$ & 0.018 & -0.167 & -0.044 \\
\hline Anchorage (Skiing) & $1942-2004$ & -0.020 & 0.031 & -0.017 & $-0.137^{*}$ & -0.120 & $-0.153^{*}$ \\
\hline
\end{tabular}

* Significant at 0.05 level.

King Salmon during spring and summer are statistically significant, indicating that the climatic contribution has significantly improved the quality of the sightseeing season. Conversely, the FoIC for skiing has decreased. When the entire period is tested, this decreasing trend is significant only during spring, but when the past three decades are tested, it is significant during both winter and spring. Lastly, the annual FoIC for sightseeing has increased significantly over $1943-2005$, while the annual FoIC for skiing in Anchorage has decreased significantly only in the past three decades.

\section{Climate Change and Alaska's Seasonal Patterns}

The analysis above reveals that the overall quality of weather conditions for sightseeing in King Salmon has improved significantly. Next we try to assess what contributed to the overall improvement (the quality of the season or the length of the season), and how changes in the seasonal patterns are associated with temperature change.

(1) Season Quality vs. Season Length: As outlined above, the tourism climate characteristics include the season's start and end dates, as well as the season's quality, measured as the frequency of ideal conditions during specified time periods. An increase in the annual quality could be a direct result of improved climate conditions during the season, or it could be driven by a lengthening season that adds high-quality days to the year. There are strong correlations between the annual frequency and several other variables: seasonal frequency, the start day, and the end day of the season (Table 4). In King Salmon, the summer frequency of ideal conditions for sightseeing has the strongest correlation with the annual frequency; spring has the secondhighest correlation. The correlation between the first day of the season and the annual frequency is also very strong. In Anchorage, the winter frequency of ideal conditions has the strongest correlation with the annual frequency of ideal conditions for skiing. The end date has a higher correlation with annual frequency than does the start day. These findings imply that 1) the annual frequency of ideal conditions is influenced by both the quality of the main season (summer at King Salmon, winter at Anchorage) and the timing of the start and end days of the seasons; 2) the frequency of ideal conditions during the main season is the strongest single contributor to the annual frequency.

(2) Seasonal Pattern Change vs. Temperature Trend: Table 5 shows that the average temperature in both King Salmon and Anchorage has increased significantly during
TABLE 4. Coefficients of correlation between annual and seasonal Frequencies of Ideal Conditions (FoIC) and between annual FoIC and start and end dates of season. All coefficients are significant at the 0.01 level.

\begin{tabular}{lccccc}
\hline \hline & Spring & Summer & Fall & \multicolumn{2}{c}{ Start Day End Day } \\
\hline King Salmon (Sightseeing) & .778 & .925 & .626 & -.724 & .495 \\
& Fall & Winter & Spring & Start Day End Day \\
\hline Anchorage (Skiing) & .666 & .722 & .638 & -.404 & .471 \\
\hline \hline
\end{tabular}

the last half-century. However, the positive trends are not significant in every month - temperature in the spring and summer has increased the most. This unevenness of the trend is also true for the frequency of ideal condition for the specific tourism activities. The trend of frequency of ideal condition is significant only in the spring months for both sightseeing in King Salmon and skiing in Anchorage.

A comparison between the monthly trend of temperature and frequency of ideal conditions shows that a large change in average temperature is not necessarily followed by a large change of frequency of ideal conditions for a specific tourism activity. For example, although the increases of temperature during summer months are large and statistically significant, the change of frequency of ideal condition for sightseeing can be very small (e.g., July). The same situation holds for September temperatures and skiing in Anchorage. Only in the spring season are large changes in average temperature accompanied by large changes in the frequency of ideal condition, implying that weather conditions for both sightseeing in King Salmon and skiing in Anchorage are more sensitive to temperature change in spring than in other seasons.

\section{DISCUSSION AND CONCLUSION}

The study demonstrates a new method of quantifying daily-level tourism climate seasonal patterns, which can be calibrated to match the specifics of any outdoor-oriented tourism activity. The study's main contributions to the emerging literature on climate and tourism are both theoretical/methodological and destination/activity-specific.

The methodological contribution includes the use of the newly developed tourism climate index to explore changes in tourism climate seasons. We demonstrated that the tourism climate seasonal patterns, derived from hourly data and 
TABLE 5. Standardized coefficients of linear regression (onto time) of the average monthly and annual temperature (T) and Frequency of Ideal Conditions (FoIC).

\begin{tabular}{|c|c|c|c|c|c|c|c|c|c|c|c|c|c|c|}
\hline & & Jan & Feb & Mar & Apr & May & Jun & Jul & Aug & Sep & Oct & Nov & Dec & Annual \\
\hline King Salmon & $\mathrm{T}$ & $0.25^{*}$ & 0.25 & $0.32^{* *}$ & $0.34^{* * *}$ & $0.34^{* *}$ & 0.24 & $0.34^{* *}$ & $0.28^{*}$ & 0.12 & -.04 & 0.12 & $0.29^{*}$ & $0.50^{k * k}$ \\
\hline (Sightseeing) & FoIC & - & - & 0.21 & $0.34^{* *}$ & 0.21 & 0.15 & 0.04 & 0.25 & 0.01 & 0.16 & 0.11 & - & $0.27^{*}$ \\
\hline Anchorage & $\mathrm{T}$ & 0.18 & 0.11 & $0.25^{*}$ & $0.34^{* * *}$ & $0.35^{* *}$ & $0.35^{\text {*** }}$ & $0.38^{* *}$ & $0.37^{* *}$ & 0.07 & -0.13 & 0.04 & $0.28^{*}$ & $0.42^{* *}$ \\
\hline (Skiing) & FoIC & -0.09 & 0.06 & $-0.25^{*}$ & -0.18 & -0.07 & - & - & - & 0.19 & 0.14 & -0.08 & -0.04 & -0.11 \\
\hline
\end{tabular}

${ }^{*}$ Significant at .05 level.

** Significant at .01 level.

displayed at the daily level, provide more detailed and valuable information than the traditional monthly distribution approach. The latter can provide information only about the overall quality of the season, while the daily level approach advocated in this paper goes beyond the overall season's quality by incorporating information about the start and end dates of the season. Because the index is ultimately based on hourly data, it provides a framework for a focus on a particular subset (or subsets) of the day if a user so desires.

A second methodological contribution is the classification of the tourism climate patterns. Using a clustering technique, this study categorized seasonal cycles at each of the two tested sites into four distinct patterns, each of which has special implications for tourism planning. The results of the initial analysis indicate that the seasonal character of tourism weather varies considerably from year to year and from decade to decade.

Beyond the methodological contribution, this study's findings are of practical importance to decision makers at the two tourism destinations analyzed. There are potential implications for the forecasting of tourism climate in the findings that (1) there are distinct classifiable tourism climate patterns and (2) a particular pattern tends to predominate over a period of several years. Specifically, there is a greater-than-chance-level likelihood that a particular year's tourism weather will have the same character as in the immediately preceding years.

The practical implications extend to the relationships between future climate change and tourism. Such relationships can benefit tourism planning for the particular regions and activities examined here. Our analysis shows that the sightseeing season in King Salmon is lengthening as it follows a (statistically significant) trend of an earlier start, with May temperatures reaching ideal levels for sightseeing more often in recent years. One example of the tourism industry response to these changes is the actions taken at Denali and Glacier Bay national parks. Tour operators at these two national parks now offer special packages to lure tourists in May (CNN, 2007). The study results also show that the overall annual frequency of ideal conditions for sightseeing in King Salmon has been significantly improved by more favorable weather during the summer season as well as an earlier start of that season. The practical implication is clear, as several surveys indicate that the quality of the season has considerable impact on tourism activity, participation, and expenditures.

Our results support the notion that future impacts of climate change on tourism seasonal patterns will most likely vary by activity and could be negative or positive. In contrast to the positive impact of global warming on the summer tourism season in Alaska, the impact on the winter tourism season is likely to present challenges as well as opportunities. The fact that the earlier end of the ski season was found to be statistically significant over the entire research period suggests that the seasonal pattern of skiing in Alaska is sensitive to global warming. This fact, considered together with the findings that the quality of the entire winter season for skiing has not deteriorated significantly because the quality of the weather conditions for skiing actually improved slightly in December and January (due to warming), makes it clear that the skiing industry has options for adaptation to the changing ski season climate patterns.

In summary, the impact of climate change on tourism is expected to be diverse and wide-ranging, and to depend upon location, geography, and activity. The methods proposed in this paper can be used to assess the impact of global warming on other tourism sectors and locations. As research progresses and a more comprehensive understanding of the role of climate change in tourism emerges, several major issues remain. The first has to do with the tourism climate index. More work is needed to ensure that the elements included in the index form the optimal mix of tourism, climate, and weather components. More studies that test the validity of the index by either surveying tourists directly or relating the elements to participation are needed. Moreover, the index, as well as the classification of seasonal patterns, should be applied to a larger range of destinations with diverse geographical and location characteristics. Once the applicability of the index to seasonal pattern distribution and classification is well established, research can turn to modeling the relation between climate and tourism volume. If these relations are established across different locations and activities using historical data, the ultimate goal of projecting future tourism changes caused by anticipated changes of various climate elements can be attempted. 


\section{ACKNOWLEDGEMENTS}

This work was supported in part by the National Oceanic and Atmospheric Administration through the Alaska Center for Climate Assessment and Policy and by the National Science Foundation through Grant ARC-0652838. We thank Bas Amelung and two anonymous reviewers for their helpful comments on the original manuscript.

\section{REFERENCES}

ACIA (Arctic Climate Impact Assessment). 2004. Impacts of a warming climate. Cambridge: Cambridge University Press. $140 \mathrm{p}$.

-2005. Arctic climate impact assessment: Scientific report. Cambridge: Cambridge University Press. 1042 p.

Ahas, R., Aasa, A., Mark, Ü., Pae, T., and Kull, A. 2007. Seasonal tourism spaces in Estonia: Case study with mobile positioning data. Tourism Management 28(3):898-910.

Alaska Climate Research Center. 2009. Temperature change in Alaska. http://climate.gi.alaska.edu/ClimTrends/Change/Temp Change.html.

Alaska Native Science Commission. 2005. http://www.ser.org/ files/ppt/Elaine\%20Abraham\%20PPT.pdf.

Alaska Office of Tourism Development. 2006. Alaska visitor volume and profile, summer 2006, executive summary. http:// www.commerce.state.ak.us/oed/toubus/research.htm.

Alaska Travel Industry Association. 2006. Tourism: It's everyone's business. Alaska's visitor industry: 2006 report. http://www. alaskatia.org/govtrelations/PDF/Alaska_Tourism_Report Card_2006.pdf.

Amelung, B., and Viner, D. 2006. Mediterranean tourism: Exploring the future with the tourism climatic index. Journal of Sustainable Tourism 14(4):349-366.

Amelung, B., Nicholls, S., and Viner, D. 2007. Implications of global climate change for tourism flows and seasonality. Journal of Travel Research 45(3):285-296.

Anderson, H.R., Tatham, R., and Black, W. 1998. Multivariate data analysis. Upper Saddle River: Prentice Hall.

Bartlein, P., Whitlock, C., and Shafer, S. 1997. Future climate change in the Yellowstone National Park Region and its potential impact on vegetation. Conservation Biology 11(3):782-792.

Baum, T., and Lundtorp, S. 2001. Seasonality in tourism. London: Elsevier Science.

Becken, S., and Hay, J.E. 2007. Tourism and climate change. Clevedon, United Kingdom: Multilingual Matters Ltd. 329 p.

Bigano, A., Hamilton, J.M., and Tol, R.S.J. 2006a. The impact of climate on holiday destination choice. Climatic Change 76:389-406.

- 2006b. The impact of climate change on domestic and international tourism: A simulation study. FNU-58. Hamburg, Germany: Hamburg University and Centre for Marine and Atmospheric Science.

Bock, H.H. 1985. On some significance tests in cluster analysis. Journal of Classification 2:77-108.
Braun, B.M., and Rungeling, B. 1992. The relative impact of convention and tourist visitors on a regional economy: A case study. International Journal of Hospitality Management 11(1):65-71.

Breiling, M., and Charamza, P. 1999. The impact of global warming on winter tourism and skiing: A regionalized model for Austrian snow conditions. Regional Environmental Change $1(1): 4-14$.

CNN. 2007. Deals offered to lure tourists to Alaska in spring. http://www.msnbc.msn.com/id/18272025/.

Colt, S., Dugan, D., and Fay, G. 2007. The regional economy of southeast Alaska. http://www.iser.uaa.alaska.edu/Publications/ Southeast $\% 20$ Economy\%20Overview\%20final3.pdf.

de Freitas, C.R. 2003. Tourism climatology: Evaluating environmental information for decision making and business planning in the recreation and tourism sector. International Journal of Biometeorology 48:45-54.

de Freitas, C.R., Scott, D., and McBoyle, G. 2004. A new generation climate index for tourism and recreation. Proceedings of the International Society of Biometeorology, Commission on Climate, Tourism and Recreation, 9-12 June, Kolimbari, Vreete, Greece.

Dudoit, S., and Fridlyand, J. 2002. A prediction-based resampling method to estimate the number of clusters in a dataset. Genome Biology 3(7):0036.1-0036.21. http://genomebiology. com/2002/3/7/research/0036.

Foster, J.L., Robinson, D.A., Hall, D.K., and Estilow, T.W. 2008. Spring snow melt timing and changes over Arctic lands. Polar Geography 31:145 - 157, doi:10.1080/10889370802580185.

Fraley, C., and Raftery, A.E. 1998. How many clusters? Which clustering method? Answers via model-based cluster analysis. The Computer Journal 41(8):578-588.

Giles, A.R., and Perry, A.H. 1998. The use of a temporal analogue to investigate the possible impact of projected global warming on the UK tourist industry. Tourism Management 19(1): $75-80$.

Gregory, R., Failing, L., and Leiserowitz, A. 2006. Climate change impacts, vulnerabilities, and adoption in northwest Alaska. No. 06-11. Eugene: Decision Research. http://www. decisionresearch.org/Projects/Climate_Change/.

Hamilton, J.M., and Lau, M.A. 2005. The role of climate information in tourist destination choice decision-making. In: Gössling, S., and Hall, C.M., eds. Tourism and global environmental change: Ecological, social, economic and political interrelationships. London: Routledge, Taylor and Francis Group. 229-250.

Hawkings, B.A., and Porter, E.E. 2003. Relative influences of current and historical factors on mammal and bird diversity patterns in de-glaciated North America. Global Ecology \& Biogeography 12(6):475-482.

Higham, J., and Hall, C.M. 2005. Making tourism sustainable: The real challenge of climate change? In: Hall, C.M., and Higham, J., eds. Tourism, recreation and climate change. Clevedon, United Kingdom: Channel View Publications. 301-307.

IPCC (Intergovernmental Panel on Climate Change). 2001. Climate change 2001: The scientific basis. Contribution of Working Group I to the Third Assessment Report of the 
Intergovernmental Panel on Climate Change. Cambridge: Cambridge University Press.

- Climate change 2007: Climate change impacts, adaptation and vulnerability. Contribution of Working Group 2 to the Fourth Assessment Report of the Intergovernmental Panel on Climate Change. Cambridge: Cambridge University Press.

Jones, B., and Scott, D. 2006. Implications of climate change for visitation to Ontario's provincial parks. Leisure 30(1): $233-261$.

Kaser, G., Hardy, D.R., Molg, T., Bradley, R.S., and Hyera, T.M. 2004. Modern glacier retreat on Kilimanjaro as evidence of climate change: Evidence and facts. International Journal of Climatology 24:329-339.

Kennedy, E. 1999. Seasonality in Irish tourism: 1973-1995. Tourism Economics 5:25-48.

Koenig, U., and Abegg, B. 1997. Impacts of climate change on winter tourism in the Swiss Alps. Journal of Sustainable Tourism 5(1):46-58.

Lemelin, R.H., and Smale, B. 2006. Effect of environmental context on the experience of polar bear viewers in Churchill, Manitoba. Journal of Ecotourism 5(3):176-191.

Lim, C., and McAleer, M. 2001. Monthly seasonal variations of Asian tourism to Australia. Annals of Tourism Research 28(1):68-82.

Lino Grima, A.P. 1993. Enhancing resilience in Great Lakes water levels management. International Journal of Environmental Studies 44(2/3):97-112.

Lise, W., and Tol, R.S.J. 2002. Impact of climate on tourism demand. Climatic Change 55:429-449.

Lohmann, M., and Kaim, E. 1999. Weather and holiday destination preferences, image attitude and experience. The Tourist Review 2:54-64.

Maddison, D. 2001. In search of warmer climates? The impact of climate change on flows of British tourists. Climatic Change 49:193-208.

Matzarakis, A. 2001. Climate and bioclimate information in tourism in Greece. In: Matzarakis, A., and de Freitas, C.R., eds. Proceedings of the First International Workshop on Climate, Tourism and Recreation. Report of a Workshop held 5-10 October 2001, Porto Carras, Neos Marmaras, Halkidiki, Greece. $171-183$.

Matzarakis, A., and Moya, B. 2002. Concept for a climate tourism index including precipitation. 15th Conference on Biometeorology and Aerobiology joint with the International Congress on Biometeorology. American Meteorological Society, 28-29. www.mif.uni-freiburg.de/matzarakis/papers/ AMS_ISB_cuba.pdf.

McBoyle, G., and Wall, G. 1992. Great lakes skiing and climate change. In: Gill, A., and Hartmann, R., eds. Mountain resort development. Burnaby, British Columbia: Centre for Tourism Policy and Research, Simon Fraser University. 70-81.

Mieczkowski, Z. 1985. The tourism climatic index: A method of evaluating world climates for tourism. The Canadian Geographer 29:220-233.
OECD (Organisation for Economic Co-operation and Development). 2006. OECD warns climate change is threatening Europe's skiing trade. http://www.oecd.org/docu ment/22/0,2340,en_2649_201185_37825494_1_1_1_1,00.html.

Pagnan, J. 2003. Climate change impacts on Arctic tourism. Proceedings of the First International Conference on Climate Change and Tourism, 9-11 April, Djerba, Tunisia. Madrid: World Tourism Organization. Available on CD-Rom, http:// www.world-tourism.org/sustainable/climate/brochure.htm.

Pelleg, D., and Moore, A. 2000. X-means: Extending K-means with efficient estimation of the number of clusters. In: Proceedings of the 17th International Conference on Machine Learning. San Francisco: Morgan Kaufmann. 727-734.

Present Weather Code Table. 2005. http://cdo.ncdc.noaa.gov/ cdo/3505doc.txt.

Rauber, R.M., Walsh, J.E., and Charlevoix, D.M. 2008. Severe and hazardous weather: An introduction to high-impact meteorology, 3rd ed. Dubuque, Iowa: Kendall Hunt. 640 p.

Sarle, W.S. 1983. Cubic clustering criterion. SAS Technical Report A-108. Cary, North Carolina: SAS Institute Inc.

Scott, D., McBoyle, G., and Schwartzentruber, N. 2004. Climate change and the distribution of climate resources for tourism in North America. Climate Research 27:105-117.

Scott, D., Wall, G., and McBoyle, G. 2005. Climate change and tourism and recreation in North America: Exploring regional risks and opportunities. In: Hall, C., and Higham, J., eds. Tourism, recreation and climate change. Clevedon, United Kingdom: Channel View Publications. 115-129.

Scott, D., McBoyle, G., Mills, B., and Minogue, A. 2006. Climate change and the sustainability of ski-based tourism in eastern North America. Journal of Sustainable Tourism 14(4): 376-398.

Scott, D., Jones, B., and Konopeka, J. 2007. Implications of climate and environmental change for nature-based tourism in the Canadian Rocky Mountains: A case study of Waterton Lakes National Park. Tourism Management 28(2):570-579.

Slayback, D.A., Pinzon, D.A., Los, S.O., and Tucker, C.J. 2003. Northern Hemisphere photosynthetic trends 1982-99. Global Change Biology 9(1):1-15.

Smith, K. 1993. The influence of weather and climate on recreation and tourism. Weather 48(12):398-404.

Smith, L.C., Sheng, Y., McDonald, G.M., and Hinzman, L.D. 2005. Arctic lakes. Science 308:1429.

Stroeve, J., Holland, M.M., Meier, W., Scambos, T., and Serreze, M. 2007. Arctic sea ice decline: Faster than forecast. Geophysical Research Letters 34, L09501, doi:10.1029/2007GL029703.

UNWTO (United Nations World Tourism Organization). 2007. Tough challenges and major opportunities: Davos Conference on Climate Change and Tourism. http://www.unep.org/ Documents.Multilingual/Default.asp?DocumentID=517\&Arti cleID $=5676 \& 1=$ en.

Yu, G., Schwartz, Z., and Walsh, J.E. 2009. A weather-resolving index for assessing the impact of climate change on tourism related climate resources. Climatic Change 95(3-4):551-573, doi:10.1007/s10584-009-9565-7. 


\section{APPENDIX}

Departure from mean 1943-2005 annual and seasonal Frequencies of Ideal Conditions (FoIC) and mean start and end of season days for each year during that period at King Salmon and Anchorage tourist venues. Last column for each venue shows the pattern type for each year.

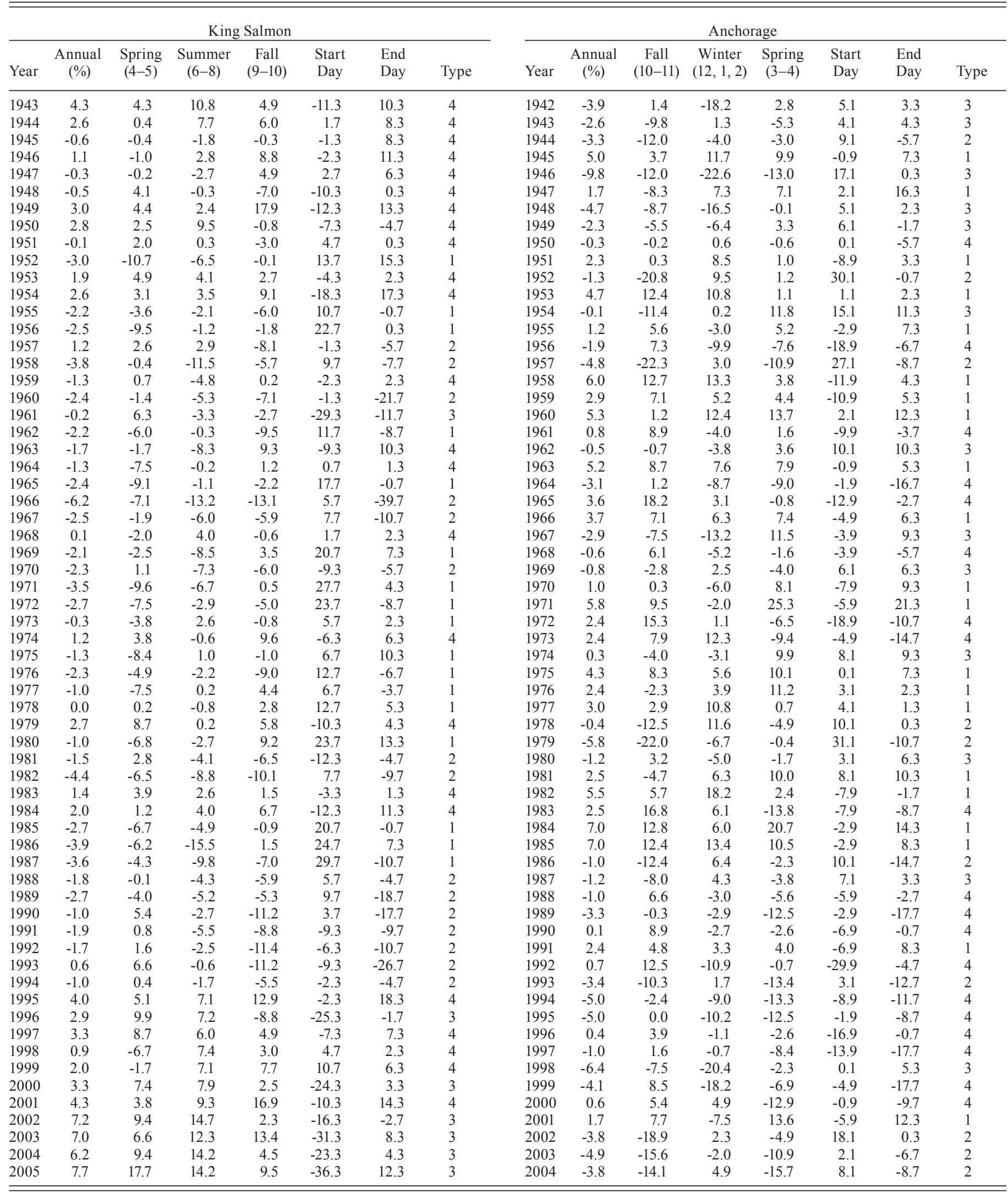

